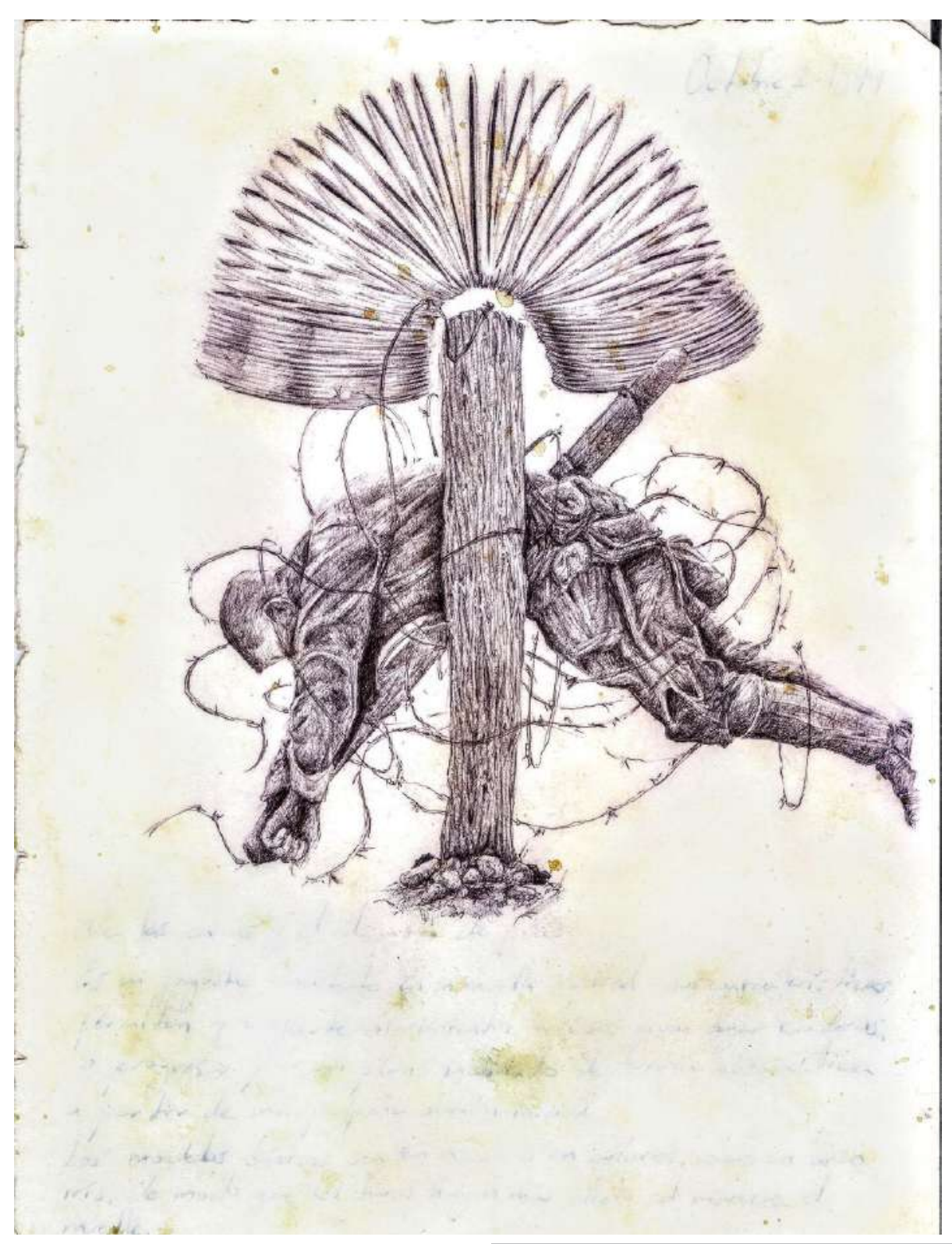

Sebastián Zea Quintero

Sin título

De la serie Del juego y el hombre Lápiz sobre papel 2017

Medellín 


\title{
Los discursos biologicistas, economicistas y terroristas de la guerra y sus implicancias en los niños, niñas y adolescentes combatientes. Una lectura crítica desde el contexto colombiano
}

\author{
Camilo Bácares Jara (Colombia)*
}

\section{Resumen}

Este artículo discute los discursos biologicistas, economicistas y del terrorismo respecto de la figura del niño, la niña y el adolescente combatiente y la tensión que tienen con la categorización de víctima de la guerra en el contexto colombiano. Para ello, se problematiza, primero, la tesis que propone a los niños, niñas y adolescentes combatientes como un producto natural y sexual; segundo, la que los formula como mercenarios; y tercero, la que niega sus derechos al señalarlos de ser terroristas. La investigación documental, basada en fuentes secundarias y testimonios, concluye que por la preponderancia política y militar de estos discursos se originan tensiones interpretativas que inhabilitan la noción de los niños, niñas y adolescentes como víctimas del conflicto armado en las confrontaciones, combates y operaciones de inteligencia militar.

\section{Palabras clave}

Conflicto Armado; Derechos del Niño; Niño Soldado; Infancia; Adolescencia; Colombia.

Fecha de recepción: noviembre de 2019

- Fecha de aprobación: abril de 2020

\section{Cómo citar este artículo}

Bácares Jara, Camilo. (2020). Los discursos biologicistas, economicistas y terroristas de la guerra y sus implicancias en los niños, niñas y adolescentes combatientes. Una lectura crítica desde el contexto colombiano. Estudios Políticos (Universidad de Antioquia), 58. pp. 112-139. DOI: 10.17533/udea.espo.n58a06

\footnotetext{
* Sociólogo. Magíster en Política Social. Correo electrónico: comalarulfo@hotmail.com - Orcid: 00000002-0508-0869 - Google Scholar: https://scholar.google.com/citations?user=Latu6zAAAAAJ\&hl=es
} 


\title{
The Biological, Economic, and Terrorist Discourses of the War and its Implications on the Child and Adolescent Combatants. A Critical Reading from the Colombian Context
}

\begin{abstract}
This article calls into question the discourses based on biological, economic, and terrorist theories about the figure of the child and adolescent combatants, and the tension they arise with the category of the child and the adolescent understood as a victim of war in the Colombian context. To this aim, the study problematizes the thesis that proposes adolescent and child soldiers as natural and sexual products; as well as, the discourse that considers them as mercenaries; and, the one that denies their rights by characterizing them as terrorist. The documentary research, based on secondary sources and testimonies, concludes that due to the political and military preponderance of these discourses, interpretative tensions that disable the notion of the child victim in confrontations, combats, and military intelligence operations emerge.
\end{abstract}

\section{Keywords}

Armed Conflict; Rights of the Child; Child Soldiers; Childhood; Adolescence; Colombia. 
La guerra no es simple. Exige mucho tiempo de cálculo. Tiene un discurso pacifista y una esmerada justificación moral. Nunca dice «yo soy la guerra». Dice otras cosas (Montemayor, 2007, p. 9).

\section{Introducción}

Las ideas que han delimitado y, en los últimos años, definido las causas, las formas de interpretación y los procedimientos institucionales para tratar a los niños, niñas y adolescentes (NNA) combatientes provienen de muchas disciplinas y campos. Además de las prevalentes, es decir, las que se asientan en coordenadas jurídicas y psicosociales para delimitar al NNA desvinculado de la guerra como víctima (Bácares, 2015), hay unas contrapuestas que establecen e impulsan marcos definitorios totalmente distintos. En una curiosa contradicción, los estudios internacionales y varios enfoques dentro de los estudios sobre la guerra han propuesto un conjunto de paradigmas que responsabilizan o individualizan en los NNA — por cuestiones de todo tipoel asunto del reclutamiento y de su participación en los conflictos armados.

Por supuesto, dichas miradas nada tienen que ver con las tesis que se desvían de la significación oficial de la vulnerabilidad, la maleabilidad y la vinculación forzada de los NNA combatientes a lo bélico, a saber, con las que han problematizado que los sujetos de la niñez pueden devenir en personas con agencia, mando y poder (Jilmar, Amador y Delgadillo, 2010), o perseguir fines de transformación social en las confrontaciones armadas (Rosen, 2005; Molano, 1999; 2017, febrero 17). En las teorizaciones biologicistas, economicistas y terroristas de la guerra, la infancia carece de una disquisición política y se diluye en un fenómeno delincuencial, instintivo y mercenario, esto es, en las mismas premisas interpretativas con las que se dilucidan los móviles de alistamiento que determinan que la población adulta haga parte de la guerra. En síntesis, que en los actores armados concurre una preponderancia natural por la violencia, que por medio de ella se busca el lucro propio o que sus acciones tienen como fin simplemente dañar a las personas y violar sus derechos.

En Colombia, por el acumulado de investigaciones contextuales que hay de los NNA que fungen como combatientes, queda claro que las explicaciones de su reclutamiento se asientan en otros sentidos y que la «voluntariedad» se entiende, por lo general, como forzada $(\mathrm{CNMH}, 2017)$. Aun así, las ideas que el biologicismo, el economicismo y la discursividad terrorista hacen de 
los NNA combatientes sí tienen cabida en las declaraciones institucionales, comunicacionales y académicas que comprenden, indiferenciadamente, a la población guerrillera y, a veces, a la paramilitar como un todo homogéneo en lo etario y motivacional con base, fundamentalmente, en el planteamiento narcoterrorista o criminal (Pécaut, 2001). Por lo que, entre estas dos vertientes - la particular, que reconoce al NNA como víctima, y la que lo lee bajo otros paradigmas responsabilizantes - existe una tensión que puede derivar en la pérdida de eficacia de la ordenanza que señala al NNA desvinculado de los grupos armados ilegales en el país como merecedor de un respeto por sus derechos en el plano de la contienda militar. Téngase en cuenta que «la caracterización de un conflicto conlleva a su turno una caracterización de los actores armados: no es igual caracterizar al adversario del Estado como una guerrilla que como un grupo terrorista» (Pizarro, 2002, p. 164). En este caso puntual, dicha determinación tiene implicancias hasta en los NNA que conforman la tropa guerrillera y paramilitar, dado que entre definir a un NNA combatiente como víctima de la guerra y englobarlo en otros discursos como resultado de su instinto, de su afán de captar rentas o de su deseo de hacer parte de una guerra contra la sociedad hay una distancia enorme y unas consecuencias políticas y militares distintas.

Por lo anterior, el artículo en cuestión propone discutir, desde el escenario colombiano, las formulaciones y señalamientos sobre los NNA combatientes que anidan en tales disertaciones en pro de cuestionar su universalidad, su aceptación discursiva y sus aplicaciones locales, recurriendo a fuentes secundarias y testimonios.

\section{El biologicismo, la guerra y la infancia}

En la historia de la guerra siempre han preponderado los esfuerzos por naturalizarla y por cercar a quienes actúan en ella como sujetos heterónomos, sin importar su edad o el hecho de que fuesen adultos o NNA. La antigua anécdota del patricio Julio Próculo en Roma puede que sea la madre de todas las explicaciones de este tipo. Tras la desaparición de Rómulo luego de una tempestad, este le diría en un sueño que la predestinación los obligaba a expandir un imperio por medio de las armas: «los dioses han decidido que un día la ciudad de Roma sea la cabeza del mundo, cultiven por tanto el arte militar y sepan, y así lo transmitan a su descendencia, que ningún poder humano podrá resistir a sus armas» (Ramírez Batalla, 2015, p. 13). 
Durante la edad media y la época colonial esta matriz comprensiva del mundo siguió teniendo adeptos. Los cristianos medievales veían en las derrotas o en las victorias militares «signos divinos de aprobación o censura» (Alvira, 2008, p. 97), al punto de que «la victoria era la prueba suprema del favor de Dios [...] y si el pecado estaba presente en un ejército, incluso si combatía en una guerra justa y sagrada, Dios abandonaría a los suyos» (p. 99). De igual forma, de acuerdo con el virrey Caballero y Góngora, «el hambre, la guerra y la peste eran los tres grandes despertadores de que el Señor se valía para castigar el pecado y la ingratitud humana» (Jurado, 2004, p. 679); por ello, una acción de carácter guerrerista —a partir de esta lógica- durante el imperio español se reducía a una penitencia a gran escala para purgar las faltas sociales e individuales. Posiciones que, en la actualidad, continúan a su modo y con otros esquemas despolitizantes de la violencia.

Uno muy famoso es el de la tesis de las nuevas guerras (Kaldor, 2001), que propició la creencia de que muchas de las rivalidades étnicas, tribales y religiosas que explotaron tras la caída del muro de Berlín se fundaban en hechos ancestrales atados a su propio desarrollo y autonomía. No obstante, una de las expresiones bélicas más significativas de finales de la década de 1990, históricamente sustentada en una explicación biológica, contradice esta situación. En efecto, lo ocurrido en Ruanda durante el genocidio de 1994 respondió a los efectos de una antropología colonial corporal de principios del siglo XIx, la cual dispuso diferenciaciones biológicas que se extendieron a los campos de la cultura, de la política y, como es evidente, al de la guerra:

La creencia de que los hutus y los tutsis eran grupos étnicos diferenciados parece haberse forjado con el colonialismo británico y el célebre explorador John Hanning Speke, quien «descubrió» y bautizó el lago Victoria en 1859 [...]. Pensaba que las divisiones que observó en la sociedad era producto de causas naturales; según Speke, en esta región de África central existía una raza superior, bastante diferente del orden común de los nativos [...]. Eran superiores y demasiado elegantes para ser «negros corrientes»; eran más altos y sus narices más estrechas. [...]. En 1933, la administración belga elaboró un censo y equipos de burócratas belgas clasificaron a la población entre hutus, tutsis o twas. Todo ruandés fue censado y medido: altura, largura de nariz, forma de ojos. Cada persona fue clasificada: los tutsis eran los más altos, los hutus eran más bajos y más anchos, aunque para muchos ruandeses no era posible determinar la etnicidad sobre la base 
Los discursos biologicistas, economicistas y terroristas de la guerra y sus implicancias...

de una apariencia física. Los ruandeses del sur eran generalmente de orígenes mixtos y la mayoría de los ruandeses de procedencia mixta fue incluida en la denominación «hutu». Sin embargo, muchos de ellos poseían los típicos rasgos tutsis, eran altos y espigados (Melvern, 2007, pp. 31-34).

Por otra parte, la psicología y la etología - poniendo a Freud y a Lorenz a la cabeza - han impulsado la idea de que la guerra se nutre del desfogue de pulsiones de muerte y de instintos de agresión que sumados validan la aniquilación de un contrario (Romero, 2008). Así, desde una postura filogenética, se ha llegado a plantear que la guerra es el resultado de un desarrollo hipertrófico, cuando en «alguna etapa de nuestra evolución, los primates homínidos que dieron origen al hombre» (Palacio, 2003, p. 59) se defendieron de los peligros que provenían de su propia especie. Igualmente, en la antropología han tenido lugar posturas como la de Sherwood Washburn, que sugieren que los seres humanos se abocan por la guerra debido a una psicología del carnívoro que encuentra su origen en las primeras cazas en el pleistoceno medio y que en la cotidianidad se expresa en la facilidad para los juegos bélicos que tienen los NNA (Fromm, 2004).

Por último, en otros intentos de restringir los actos de la guerra a sucesos biológicos, las posturas más recientes han optado por registrar que las violaciones a los derechos humanos son derivadas de desórdenes mentales y de patologías (Torrijos, 2015). Ante esto, es indudable que la guerra enferma y reproduce un sinfín de conflictos psíquicos y traumas, como lo comprueban las tasas de suicidio de las fuerzas armadas (El Tiempo, 2019, junio 12), el famoso pabellón médico creado para los oficiales peruanos que enloquecieron luchando contra Sendero Luminoso (Uceda, 2004) o los estudios de Ignacio Martín-Baró (2000). Empero, estas disposiciones planteadas como factores desencadenantes y no como reverberaciones, apuntan a un deterioro de las responsabilidades penales y políticas de los actores, y a una refrendación de la inevitabilidad de las hostilidades en las que a los NNA les cabe un papel principal y casi sempiterno (Ródenas, 2003).

Básicamente, la actuación bélica de los NNA puede leerse en cualquiera de las nociones recién bosquejadas. Su acción militar sería posible sustentarla por una ordenanza divina, una propensión biológica o una enfermedad. Justo esto es lo que hace Herfried Münkler (2005) cuando plantea sobre las nuevas guerras que una de las grandes características 
que las definen es el reclutamiento masivo de NNA. Afirmación, de por sí, ambigua, teniendo en cuenta el alistamiento y participación de los NNA en los pasados conflictos armados: en la guerra civil de los Estados Unidos combatieron entre 250000 y 420000 NNA (Rosen, 2015); en la Primera Guerra Mundial se estima que fallecieron 120000 NNA como miembros del Ejército británico (Winterberg, y Winterberg, 2015); y en conflictos latinoamericanos, como la guerra de la Triple Alianza (Potthast, 2005) o las nueve grandes guerras civiles que Colombia experimentó en el siglo xIx (Bácares, 2017; Jaramillo, 2007; Reina, 2012; Tovar, 2001), su presencia fue cotidiana y casi institucionalizada.

Münkler (2005) asevera que uno de los móviles del ingreso a la milicia de los menores de edad hombres — sin esclarecer el de las niñas- es la descarga de su libido y que dicha propensión facilitaría comprender el aumento de las violaciones a las mujeres en los conflictos africanos y la mutilación de sus genitales. Apoyándose en Michael Ignatieff, el politólogo alemán sostiene y simplifica la cuestión aduciendo que la brutalidad y el incremento de la violencia contra la mujer en las nuevas guerras es consecuencia de una mera necesidad física de los adolescentes o de la «sexualidad salvaje del varón adolescente» que dota al arma y al uniforme de «un explícito significado fálico» (Münkler, 2005, p. 26). De este modo, la opción por las políticas o las reglamentaciones militares diseñadas para atacar los cuerpos femeninos en aras de explotar créditos simbólicos de dominación y de terror entre la población civil quedan desechados, pese a que se sabe que la violación sexual, indistintamente en los conflictos armados internos, se ha invocado como un arma de guerra para humillar, alterar la integridad, avergonzar y tratar como objetos a los contrarios (Lair, 2003, p. 101).

Aunque, si de explicaciones biologicistas más abarcadoras se trata, quizás la más reduccionista de todas es la que argumenta que los hombres jóvenes, para llevar a cabo su instinto de reproducción, requieren captar recursos para mejorar su estatus, pues las «mujeres tienden a ser selectivas en cuanto a sus parejas sexuales» (Rubio y Salcedo, 2006, p. 7). De esta forma, la rueda de la violencia, incluso la política, se echa a andar cuando esos jóvenes y adolescentes buscan las maneras de garantizarse un ascenso social, con la condición inexorable de vivir una desigualdad socioeconómica y habitar territorios donde predomine un desequilibrio de parejas, es decir, que haya 
más hombres que mujeres disponibles para la reproducción. Según esta visión, los jóvenes que habitan los lugares más comunes de un conflicto armado, como el colombiano, se incorporan a las organizaciones armadas ilegales para obtener poder y así desplegar una estrategia con fines de prolongar sus genes. En una suerte de resumen de sus sentencias: «a mayor superávit de hombres en edad de casarse, mayores niveles de violencia» (p. 19) o «entre mayor es el desequilibrio de la población por géneros mayor es la probabilidad de influencia guerrillera» (p. 21).

Desde luego, la anterior hipótesis - la cual se enmarca en un proyecto por entender las violencias en clave afectiva y de placer, en demérito de razones más estructurales y objetivas (Rubio, 2007) — es provocadora, lo que no quiere decir que sea válida o suficiente para la comprensión de los orígenes y la permanencia de la violencia política y de los roles de los NNA en ella. A sus postulados se puede contraponer la militancia de las niñas y de las mujeres en una tropa militar, ante una teoría con visos machistas en la que ellas se conciben como inactivas y pasivas. Basta señalar la inmensa convocatoria de mujeres que tuvo la guerrilla de Sendero Luminoso en Perú (Vega-Centeno, 1994), o la función significativa que tuvieron en su contraparte paramilitar en los Comités de Autodefensa (Boutron, 2014); además, ¿cómo explicar, atendiendo a esta proposición biologicista, que en Colombia, entre 1960 y 2016, de 16879 NNA reclutados por grupos armados ilegales 29\% corresponda a niñas y adolescentes mujeres? (CNMH, 2017). O, ¿de qué forma se podría interpretar la conjetura de la exploración en la guerra para dar rienda a la sexualidad, cuando en una línea interpretativa muy informada - como también oficial e insistente de la criticada vulnerabilidad en la infancia (Rosen, 2005) — la vinculación de los NNA a la guerra se detalla como producto de coerciones, amenazas y presiones violentas?

En una perspectiva histórica, el reclutamiento en Colombia durante el siglo xix es ilustrativo, dado que las tropas oficialistas conservadoras entraban a los pueblos en los días de mercado y acorralaban a los presentes, incluidos los NNA, para luego marchar con ellos atados del cuello, en lo que se conocía como reclutamiento por lazo (Jaramillo, 2007). De igual manera, en el conflicto armado colombiano contemporáneo el rastreo y la incorporación violenta de NNA han tenido vigencia por decisión de las guerrillas y de los escuadrones paramilitares, anulándose con ello el mercado de la soltería como el motor del enganche a la guerra: 
Entonces me coloraron un pasamontañas y me llevaron; después que me lo quitaron aparecí en el monte y me dijo un comandante que si seguía llorando me mataba, me tenía que tragar las lágrimas y que de ahora en adelante era para ellos uno más del grupo. Testimonio Hombre, 15 años, Autodefensas Unidas de Colombia.

[...] Un día yo iba para el corte de la mora, sano ahí, cuando llegaron y así iban como bravos porque llegaron y se encontraron conmigo y me dijo usted, ya, que se iba con nosotros, vámonos. Sin yo decirles nada y me tocó irme con ellos. Llegamos a un campamento y duré como tres días por ahí babeando solo, con ellos, pero sin nada, y como a los tres días me dieron un fusil y un chaleco y de ahí para acá no supe nada más de mi familia. Testimonio Hombre. 16 años. Ejército de Liberación Nacional (Bácares, 2014, pp. 63 y 65).

Por lo visto, la posibilidad de que el instinto evolutivo de los NNA tome curso y se imponga como el factor determinante del NNA combatiente colombiano es discutible, si se coteja con datos cualitativos como los esbozados. Por ahora, lo que sí es cierto es que los abordajes biologicistas escapan del campo académico y tienen efectos en el tratamiento militar de la infancia estimada como combatiente o señalada de colaboradora de un grupo armado legal o ilegal. Por ejemplo, inspirado en él, las fuerzas armadas colombianas lanzaron en 2002 sobre el territorio araucano más de dos millones de calendarios de bolsillo con fotografías de mujeres semidesnudas para estimular la deserción guerrillera (Rubio, 2007); y siguiendo parámetros biométricos, el paramilitarismo, en la conquista territorial del sur del país a mediados de los noventa, acusó a los campesinos — NNA y a adultos por igual- de ser guerrilleros a partir de ciertas indicaciones en los cuerpos, como las marcas en los hombros, las manos, la delgadez o la palidez (CNMH, 2012).

Por lo que refiere a la interpretación del NNA combatiente colombiano, el biologicismo lo ha afectado desde, por lo menos, la década de 1960. En primer lugar, por la carrera que hicieran las tesis de la anormalidad psicológica, que estiman que quienes ingresan por su cuenta a las organizaciones armadas ilegales —incluyendo a los NNA — lo hacen empujados por rasgos psicopáticos, narcicismos, hipomanías, desórdenes mentales, frustraciones y déficits neuropsicológicos desarrollados en la niñez (Hudson, 1999). En segundo término, la animalización retórica del subversivo y la aplicación al límite de esa visión del «comunista» como un «cáncer que carcomía la vida 
nacional, su progreso, sus recursos y su tranquilidad» (Uribe, 2007, p. 136) o como «una carga organicista-fisiológica en la que el enemigo es entrevisto como una enfermedad que debe combatirse» (Toche, 2008, p. 88) supuso que en las embrionarias Fuerzas Armadas Revolucionarias de Colombia-Ejército del Pueblo (FARC-EP) las operaciones militares estatales golpearan también a los NNA adscritos consanguíneamente a la guerrilla. Como lo documenta una misiva enviada por Manuel Marulanda al Congreso de la República el 5 de agosto de 1964 - que deja constancia de nombres, apellidos y edades-, en el ataque a Marquetalia murieron dieciséis NNA hijos de combatientes, resultado de la violencia estatal que allí se implementó (Uribe, 2007, p. 134).

En conclusión, de cara a otras lecturas de la infancia en la guerra, el biologicismo, entendido como un conjunto de discursos y saberes que proponen «la violencia y la guerra como algo consustancial con la naturaleza humana, y, por tanto, como algo inevitable» (Ródenas, 2003, p.23) respalda respuestas militares de eliminación similares para los NNA y adultos combatientes, o en aquellos acusados de apoyar a un bando de la guerra, con sustento en la hipótesis de su desviación natural o de que se les entienda como irrecuperables, anómalos, intérpretes de la insania o peligros latentes. ${ }^{1}$

\section{El economicismo, la guerra y la infancia}

La hipótesis más preponderante de las últimas décadas, en lo referente a la aparición y continuidad de las guerras, es que - tomando como base el continente africano y exportando esa idea a otros lugares - las hostilidades surgen por cuenta de una conjunción de variables de corte económico que se pueden probar estadísticamente. De hecho, se han sugerido cuatro correlaciones para cimentar esta vertiente interpretativa: la primera indica que en los países de renta baja hay más probabilidades de que estalle una guerra y que al hacerlo la reducción del producto interno bruto es inminente; la segunda, que el crecimiento lento y el crecimiento negativo contribuyen al surgimiento de la guerra; la tercera asegura que la estructura geográfica de un país, «montañas, selvas y enormes extensiones de territorio escasamente

\footnotetext{
${ }^{1}$ Otros ejemplos latinoamericanos donde este enfoque de la inevitabilidad tuvo lugar son: El Salvador, donde a los NNA el Ejército los mataba desde tempana edad en las zonas rurales para que no se convirtieran en guerrilleros (Danner, 2016); igual que en Perú, donde el Ejército, en su lucha contra Sendero Luminoso, consideraba que en las comunidades andinas - los niños, adultos y ancianos«todos eran malos elementos» (Comisión de la Verdad y Reconciliación, 2003a, p. 597) y, por ende, objetivos militares.
} 
poblado» (Collier et al., 2004, p. 73), auspician el estallido y rebrote de una guerra; la cuarta, que la «dependencia económica de las materias primas de exportación — petróleo, diamantes, y productos por el estilo - aumenta sustancialmente el riesgo de guerra civil» (Collier, 2011, p. 47).

Sin embargo, estas propuestas son tan válidas como inciertas, en especial, si se contraponen a otros contextos. Particularmente, los conflictos armados generan decrecimientos y pérdidas, así como acumulaciones e incrementos de capital, tanto para los sectores legales como ilegales. El caso colombiano es una muestra clara de estos dos efectos tan distantes. Entre 1990 y 1998 los costos del conflicto armado representaron entre $1,5 \%$ y $4 \%$ del producto interno bruto anual. Costos, sobre todo directos, que si se desagregan dejan ver que la economía nacional por la destrucción de la infraestructura petrolera perdió entre 1999 y 2003 COL $\$ 817654$ millones; y en lo que refiere a los atentados a las torres de conexión eléctrica y de telecomunicaciones —en el mismo periodo— otros COL\$134 871 millones (Álvarez y Rettberg, 2008).

En lo específico, de la inversión social para la infancia el saldo también tiende a ser negativo. En un estudio financiado por el Programa de Naciones Unidas para el Desarrollo (Sánchez y Díaz, 2005), se puso en evidencia [122] que debido a la injerencia de las FARC-EP en varios territorios las tasas de escolarización en educación secundaria decrecieron 6,71\% al año entre 1996 y 2002; asimismo, en el área de la salud 480000 personas quedaron por fuera del sistema de atención subsidiado entre 1998 y 2003 por la apropiación de los recursos que en las regiones fueron sustraídos por los grupos paramilitares en asocio con funcionarios públicos (Sánchez y Díaz, 2005, p. 43).

Ahora bien, desde otro ángulo, la guerra arruina tanto como beneficia a quienes la patrocinan para acumular riqueza en un ámbito transnacional e interno (Ramonet, 2005). Se calcula que de los 1300 millones de dólares aprobados inicialmente para el Plan Colombia «sólo un 13\% llegó a manos del gobierno colombiano para mejorar sus estructuras de seguridad. El 87\% fue a parar a las cajas de las empresas estadounidenses» (Uesseler, 2007, p. 140). La contrarreforma agraria propiciada por las autodefensas en favor de terratenientes (Koessl, 2015) y las alianzas entre las multinacionales bananeras ubicadas en Colombia con los grupos paramilitares, en lo que atañe a la rentabilidad empresarial, son otras pruebas que se pueden agregar a lo descrito (Verdadabierta.com, 2017, febrero 3). Precisamente, en 2008 
Chiquita Brands aceptó ante la justicia norteamericana haber entregado aportes a las Autodefensas Unidas de Colombia (AUC), «por medio de la creación de falsas cuentas de contabilidad, al utilizar la figura del incremento salarial a sus empleados en Colombia» (Fajardo, 2011, p. 33). Esta empresa y otras como Dole, nombradas en las versiones de ex jefes paramilitares de la talla de Salvatore Mancuso, «pagaban impuestos porque eran como un estado en la zona, y porque se les proporcionaba la protección que les permitía seguir haciendo inversiones y un beneficio económico» (Fajardo, 2011, p. 51).

De esta suerte, si el economicismo se amplía por fuera de lo que se denomina el club de la miseria su conceptualización pierde legitimidad, sin que escape de esto lo formulado sobre los NNA y los jóvenes combatientes, o lo afirmado sobre la conclusión general de que las guerras en la actualidad se dan para controlar recursos naturales y facilitar el enriquecimiento personal de sus líderes. Si bien es cierto que en estos planteamientos se reconoce que organizaciones como la ugandesa Frente de Resistencia del Señor «recluta sus efectivos a base de rodear escuelas apartadas y prenderles fuego» (Collier, 2011, p. 59) o que «en Burundi, los grupos rebeldes reclutaban a los niños por la fuerza, comprando niños callejeros de Kenia a un precio de US $\$ 500$ dólares por cada 150 muchachos» (Collier et al., 2004, p. 59), su posición más extendida determina que el ingreso de los NNA a las hostilidades se contempla mayormente como un acto de liberación de la pobreza o como una especie de mercenarismo especulativo:

En un entorno de pobreza sin esperanza, los varones jóvenes, que son los reclutas de los ejércitos rebeldes, salen bastantes baratos. La vida en sí no vale mucho y el alistamiento en un movimiento rebelde ofrece a esos jóvenes una pequeña oportunidad de enriquecimiento [...]. Esta especie de alistamiento a las rebeliones se asemeja a cómo se produce la incorporación a las bandas de narcotraficantes de Estado Unidos. Un conocido estudio de una banda de Chicago puso de manifiesto que los jóvenes se unían a ella y estaban dispuestos a trabajar prácticamente gratis porque les atraía la pequeña oportunidad de ganar mucho dinero si lograban ascender en el escalafón de la banda (Collier, 2011, pp. 46-47).

Alejada de la motivación económica, la experiencia colombiana disiente o le cuesta encajar del todo en esta comprensión oficial que limita 
la anexión a la guerra a un simple estímulo monetario. Y no es la única. Utilizando datos de Mozambique, Etiopía y de la Segunda Guerra Mundial se ha postulado que los NNA pueden enlistarse por su altruismo político (Rosen, 2005), o que el ingreso de los NNA al senderismo se debió a una lucha y reclamo generacional de los más jóvenes a los más viejos (Degregori, 1991) para desplazar «violentamente a las personas mayores de las posiciones de poder y prestigio en sus propias comunidades» (Comisión de la Verdad y Reconciliación, 2003a, p. 173). En Colombia, la visión economicista como factor explicativo del reclutamiento de menores de edad, ante todo, puede encontrar asilo en el relato de los NNA paramilitares y en las tasas cuantitativas que revelan una relación contractual $(\mathrm{CNMH}, 2017$; Ugarriza y Nussio, 2015). En sus declaraciones, es reiterativo el ofrecimiento salarial por parte de la organización o una especie de contrato informal que promete un estipendio mensual, bimensual o trimestral, en función del rol y del mando que se alcance:

Un patrullero normal se ganaba $\$ 350000$ allá donde yo estaba, ya si es un segundo de escuadra se está ganando $\$ 400000$, un comandante de escuadra se estaba ganando $\$ 450000$. Un segundo de contraguerrilla estaba ganando $\$ 550000$, un comandante contraguerrilla estaba ganando $\$ 650$ 000. Un segundo de compañía se estaba ganando como $\$ 800000$ y un comandante de compañía se estaba ganando como $\$ 950$ 000. Un primero de columna estaba ganando por ahí un millón y punta, y un comandante de columna estaba ganando como $\$ 1$ 500 000. Después del comandante de columna venía el comandante de zona, que ya mandaba por ejemplo 3 o 4 columnas, ya mandaba una zona él, después por ejemplo venía el segundo de zona, después venía el comandante de zona y ahí ya venía el comandante militar. Testimonio Hombre. 16 años. Autodefensas Unidas de Colombia (Bácares, 2014, p. 170).

Caso contrario, la mayoría de los NNA desmovilizados de las guerrillas han dado testimonio de que los pagos nunca se realizaron (Springer, 2012) o que estando en ellas alguna vez recibieron dinero $-40 \%$ en las FARC-EP y 20\% en el Ejército de Liberación Nacional (ELN) y el Ejército Revolucionario del Pueblo (ERP)— (Unicef, 2006). Esta información, evidentemente, está lejos de negar el empleo de un tipo de reclutamiento que con ofertas económicas se aprovecha de las necesidades y de las aspiraciones de los NNA de ayudar a sus familias. 
No obstante, la diferencia entre estos dos mundos es abismal, tanto que en el ELN y en las FARC-EP se considera un delito muy grave el enriquecimiento personal, la deserción con dinero y «el robo o desfalco de los dineros de las organizaciones milicianas, del movimiento de masas o de las organizaciones revolucionarias» $(\mathrm{CNMH}, 2017$, p. 348). En la insurgencia las premisas tradicionales de su discurso y práctica (Wills, 2008, junio 22) han hecho que «allá nunca le pag[uen] a nadie, allá los que manejan plata son los comandantes». Testimonio Hombre. 17 años. FARC-EP. (Bácares, 2014, p. 167). En cambio, en el paramilitarismo el dinero y el acceso al mercado se utilizan para cohesionar y garantizar la sumisión de sus integrantes (Cárdenas, 2005; Koessl, 2015, Rodríguez, 2008). Así, la mera disciplina revolucionaria de las guerrillas que castiga a quien se desvíe de ella o la violencia paramilitar contra sus propios miembros son insuficientes para cimentar y orientar a sus participantes. Por esto, la explicación economicista de Paul Collier, leída desde la infancia combatiente colombiana, termina siendo parcial o sirve únicamente para vincularla con los ejércitos ilegales que buscan fuerza de trabajo ofreciendo de antemano una paga o, en este caso, con los NNA paramilitares que mediados por bienes materiales y remuneraciones económicas conciben a la guerra como un trabajo o una forma de lucro (Bácares, 2014).

Al respecto, que los NNA paramilitares encajen más en esta comprensión economicista de ninguna manera implica que su tratamiento en el escenario militar deba desatender sus derechos o devenir en un perfil sesgado en esa variable motivacional. Pese a ello, en muchos casos a los NNA combatientes se les ha reducido a un uso contrainsurgente desde el economicismo, induciéndolos a fungir de guías a campamentos o a brindar información para la inteligencia militar a cambio de dinero (Bácares, 2014; Unicef, 2006), aun cuando esto lo prohíben los protocolos de atención a los NNA desvinculados del conflicto armado y, expresamente, el artículo 6 de la Ley de Inteligencia y Contrainteligencia, y el parágrafo 29 del artículo 41 del Código de Infancia y Adolescencia.

Ciertamente, este reduccionismo no debe sorprender, pues en Colombia la política pública de desmovilización se ha configurado para pensarse casi exclusivamente desde los incentivos económicos (Koessl, 2015), o más si se incluye en la reflexión el hecho de que las Fuerzas Armadas están acostumbradas a llevar a cabo operaciones de inteligencia con menores de edad, desarrollando en las regiones campañas cívico militares, como lo 
corroboran las veintisiete que realizaron en 2019 (ONU, S/2019/1017). En cierto modo, lo que vale la pena recalcar es que las significaciones centrales del economicismo, que leen parcialmente a los integrantes de las organizaciones al margen de la ley como codiciosos o mercenarios, provocan y avalan interpretaciones discrecionales que anulan o ponen en entredicho la noción del NNA todavía en armas y más tarde la del desvinculado como víctima de la violencia política. Esto lo sustenta, por ejemplo, la estrategia de lanzar volantes desde helicópteros con la forma de papel moneda colombiano de diferentes denominaciones, «los cuales contenían mensajes, como "sí paga desmovilizarse"» (ODDR, 2012, p. 22) para que indiferenciadamente de su edad los combatientes abandonen la guerra y , a posteriori, el ofrecimiento de delaciones pagadas a los NNA desmovilizados que los exponen a peligros y a una reinserción viciada, sostenida en la lógica del cooperante: «ì cuánto me van a dar por lo que sé?» (Bácares, 2014, p. 258). ${ }^{2}$

\section{El terrorismo, la guerra y la infancia}

La relación construida entre las premisas del terrorismo y los NNA combatientes es altamente compleja por la amplitud de definiciones y enfoques que componen al terrorismo, y por el uso político que se le da a menudo a

[126] esa expresión para mitigar la naturaleza política de las organizaciones armadas ilegales que recurren a su uso como un arma de guerra. Como lo expone Nelson Manrique (1989), existe una forma de liquidar el debate cuando se habla sobre una guerrilla, «que se ha convertido en una convención implícita; ella consiste en calificarla como terrorista» (p. 137).

Y es que la confusión es tan significativa que a quienes hoy se les designa con este epíteto por medio de decretos y declaraciones políticas, la bibliografía vigente y oficialmente aceptada de la década de 1980 los delimitaba como aliados o enemigos a partir del binomio guerra revolucionariaguerra contrarrevolucionaria, en ocasión «del apoyo que diversas naciones le prestaron a distintos grupos armados que enfrentaban regímenes marxistas»

\footnotetext{
${ }^{2}$ Esta estrategia se utilizó particularmente entre 2002-2005 y se hizo entendiendo «el dinero como una posible motivación para dejar la organización armada» (ODDR, 2012, p. 22). En la actualidad la acción del volanteo aéreo sigue funcionando con leyendas como «tráenos tus armas y explosivos y recibirás dinero a cambio», «tráiganos sus armas y explosivos, recibirá bonificación», «reciba bonificación por material de guerra». Solamente en 2019, en los departamentos del Vichada y el Guainía, fueron arrojados 130000 volantes de desmovilización (Gaori, 2019, junio 28).
} 
Los discursos biologicistas, economicistas y terroristas de la guerra y sus implicancias...

(Pizarro, 2002, p. 167). De ahí que los muyahidines afganos, la Unión Nacional para la Independencia Total de Angola de Jonas Savimbi o la Contra nicaragüense fueran para Estados Unidos asociaciones contrarrevolucionarias, sin importar sus permanentes despliegues militares en contra de los civiles ni se les estigmatizara con la denominación de terroristas en las tipologías de la guerra de la época (Pizarro, 2002).

Tras el ataque a las Torres Gemelas, la doctrina Bush fue responsable de homogeneizar los proyectos armados ilegales en el mundo como amenazas globales para los intereses estadounidenses, lo que alteró la forma de definir las acciones y la naturaleza de las guerras recientes; además, sin el estorbo de la guerra fría, se facilitó la promoción de una noción indefinida y profundamente discrecional en un sinfín de ámbitos que, por lo menos a primera vista, rindió frutos por su capacidad de puntualizar al otro bando ante la opinión pública, puesto que uno de sus rasgos fundamentales es definir, más que a un sujeto, a «una posición (la enemiga)» (Bonavena y Nievas, 2006, p. 369).

Aunque hay autores que se aferran a que la idea del terrorismo es acotada y precisa (Hodge, 2019), en el fondo, la crisis aclaratoria y la vaguedad de la postura terrorista es tal que se le puede «flexibilizar y ampliar tanto como se desee» (Bonavena y Nievas, 2006, p. 369). Su propia historia de pugnas, de falta de consensos y de definiciones plurales sin interconexiones claras lo permite imaginar así (Calmet y Costa Dal Castel, 2018; Nievas, 2015). Solo para hacerse una idea de lo recién trazado, en el mundo «durante el período 1931-1981 se dan 109 definiciones de terrorismo» (Ramírez y Jiménez, 2014, p. 181) y es hasta 1972 cuando en las Naciones Unidas aparecen por primera vez las resoluciones que lo nombran indefinidamente a causa de las tensiones que había para fijar una clara distinción entre violencia revolucionaria legítima y violencia terrorista criminal entre Estados Unidos y los países anticolonialistas (Fernández, 1999). De la misma forma, en el campo jurídico la «indefinición de terrorismo a nivel internacional ha provocado una descentralización en su regulación jurídica al dejar en manos de cada Estado la potestad discrecional de decidir qué es terrorismo y qué no lo es» (Villegas, 2016, p. 144).

Vale advertir que, a pesar de los intentos de circunscribir el terrorismo en la ilegalidad, con posturas como la del FBI o las de los manuales de las Fuerzas Armadas estadounidenses en las que «el terrorismo es un uso ilegal de la fuerza o violencia contra las personas [...]» (Torres, 2010, p. 85) o que 
es el «uso o la amenaza del uso ilegal de la fuerza o de la violencia contra individuos» (Ramírez y Jiménez, 2014, p. 182), el único acuerdo o indicador reiterativo en la baraja definitoria que existe es acerca del ataque a la población civil o, en su defecto, sobre la violación explícita del derecho internacional humanitario (Pizarro, 2002; Torres, 2010; Ramírez y Jiménez, 2014). Con esta acotación, esto es, con el señalamiento que el terrorismo puede ser la violencia premeditada contra los no combatientes o contra las comunidades no beligerantes, el rango de análisis, en lugar de limitarse, se amplía a su vez a los Estados y al ejercicio del monopolio de la violencia.

En esencia, con esta mirada la figura del NNA combatiente puede pensarse a partir de dos flancos reactivos del enfoque del terrorismo: la protección y la victimización; al unísono del que percibe a los NNA guerreros como enemigos $y$, por ese motivo, como sujetos de aniquilación. Cada uno por su cuenta, resultan predominantes en el ámbito jurídico y militar, siendo el primero una consecuencia del paradigma de los derechos de los NNA y del derecho penal internacional que ha catalogado el reclutamiento de menores de quince años como un crimen de guerra (Ramírez, 2010). En concordancia, una organización armada legal o ilegal, al asignar una u otra función a un NNA por debajo de esa línea etaria violaría el compendio del derecho internacional humanitario y se haría acreedor de ser catalogado como un aparato que comete actos terroristas, sin querer decir con esto que su propósito en la guerra se limite a esta acción.

Por contraste al reconocimiento del NNA como víctima de un delito, el proyecto discursivo del terrorismo avala la eliminación física del NNA combatiente. Durante su estadía en la guerra o al activarse una sospecha que los vincule primordialmente con la insurgencia, los imaginarios que sostienen el terrorismo apoyan su asesinato, debido a la peligrosidad que se le endosa por ser partícipe de un proyecto armado. Efectivamente, la producción teórica del terrorismo desde el Estado se sustenta en una legitimidad moral que sobrepasa a la legalidad y al derecho de los combatientes. La lógica del gobierno de Alberto Fujimori para golpear a Sendero Luminoso es un hito en este sentido: a los NNA combatientes se les condenó penalmente en juicios sumarios y con jueces sin rostro que violaban sus derechos (Bácares, 2011), y en otros casos hubo «ejecuciones selectivas de niños y niñas cuando éstos tenían relación con algún grupo subversivo» (Comisión de la Verdad y Reconciliación, 2003b, p. 598). 
En una consideración muy sencilla por la puesta en desarrollo de tres ejes que trae consigo la postura del terrorismo para delimitar el tratamiento político, militar, comunicacional y jurídico de los protagonistas de la guerra, el más básico e importante conduce a que «el terrorismo aparece como la negación de la condición humana. Así es presentado, y quienes son acusados de terroristas son privados de todo derecho humano» (Bonavena y Nievas, 2006, p. 369). El subsiguiente concierne a que el calificativo de terrorista aúpa el tránsito de un enemigo real —con quien es posible negociar y tiene un reconocimiento mínimo de contienda- a uno absoluto al que solo hay que combatir y dar de baja (Ramírez y Jiménez, 2014). En último lugar, la perspectiva del terrorismo promueve un derecho penal del enemigo que hace que, incluidos los NNA, se les considere «como meras fuentes de peligros que deben ser neutralizadas del modo que sea, cueste lo que cueste» (Torres, 2010, p. 83).

Por consiguiente, el NNA combatiente en el fragor y en la tras escena de la guerra puede ser asesinado como cualquier adulto, en especial, cuando los parámetros de definición del otro como terrorista acreditan en los actores de la guerra y en quienes se informan y guían por esos códigos lo que ya se había esbozado: que la vida del contrincante es precaria, invivible, impropia de un duelo, alejada de valer la pena, de merecer un obituario o de ser una vida a pesar de estar viva (Butler, 2006; 2010).

En Colombia, los libros testimoniales de ex guerrilleros mayores de edad, incluso de aquellos que desertaron de sus filas y rechazan la lucha armada, confirman que mientras permanecieron en la insurgencia «nadie pensaba en desertar porque el ejército no capturaba guerrilleros. Los mataba, así se hubieran entregado» (Rueda, 2009, p. 132). Puntualmente, en lo que corresponde a la infancia combatiente, un gran evento sirve para pensar la puesta en marcha de este raciocinio: la famosa operación Berlín del año 2000, con la que el Ejército le propinó a las FARC-EP el golpe militar más grande de su historia. En ella, quedó al descubierto el masivo reclutamiento forzado realizado por esta guerrilla y por su neófita columna móvil Arturo Ruíz. De acuerdo a los reportes de la época, noventa guerrilleros fueron capturados —72 eran menores de edad-y entre los muertos se contaron 20 NNA (Verdadabierta.com, 2016, agosto 27). Pero, lo que interesa subrayar es que los sobrevivientes hicieron público que en la ofensiva a varios NNA combatientes detenidos y desarmados se les disparó, y que se les recriminó 
— descontando excepciones - por su alteridad negativa, propia de un desmerecimiento de vivir:

A nosotros también nos detuvieron rapidito allá, también nos dieron pata y culatas. Con cuchillos nos cogían así, nos daban en el estómago. Nos cogieron a cien. Casi la mayoría eran menores de edad. Ahí un soldado dijo que nos iban a quemar, o sea nos trataron mal, nos dijeron que «come vacas no sé qué», nos dijeron todo hasta que llegó la Cruz Roja Internacional y arregló. Pues, yo digo prácticamente fue la que nos salvó porque los soldados decían que a nosotros nos iban a matar quemados. Que nosotros no merecíamos, no merecíamos vivir, nosotros éramos una basura para la comunidad.

[...] Mataron a nueve en el combate, había menores de dieciocho años. Había una chica que le habían herido, le colocaron un tiro acá, entonces la china estaba viva todavía, estaba bien, entonces el ejército la mató, la acabó de matar. Se llamaba Juanita. Tenía como dieciocho años (Human Rights Watch, 2004, pp. 62 y 63).

[...] Para ese entonces éramos cuatro chicas, pero una de ellas se fue con otro muchacho, otro compañero se fue a buscar comida y el ejército lo mató. Por eso teníamos mucho miedo de entregarnos al ejército y es por eso que decidimos buscar civiles para irnos con ellos a entregarnos y así evitar que el ejército no nos fuera a matar, para esa época tenía 16 años (Benposta Colombia, 2019, p. 8).

En otra dinámica muy recurrente del conflicto armado colombiano también se puede ubicar la tensión que el discurso terrorista le imprime a la consideración de víctima que tiene la niñez combatiente en el episodio del combate. Los bombardeos que habitualmente se despliegan contra campamentos guerrilleros con base en fuentes humanas y tecnológicas, demuestran que, a sabiendas de la presencia de NNA — por alertas tempranas de la Defensoría del Pueblo, de las autoridades locales y por denuncias investigativas (El Tiempo, 2019, septiembre 14; Verdadabierta. com, 2019, noviembre 8; Rojas y Aristizábal, 2019)— se privilegian los ataques con bombas para eliminar a cabecillas o a blancos de importancia. El bombardeo del 29 de agosto de 2019, diseñado para dar de baja a alias Gildardo Cucho de las disidencias de las FARC, con un saldo de ocho NNA muertos (Semana, 2019, diciembre 11), es una confirmación de este fenómeno todavía ignorado que se suma al de otros dieciséis NNA, en al menos siete acciones militares desde 2010 (Sánchez, 2019, febrero 9; 
Molano, 2019, noviembre 9). ${ }^{3}$ De este modo, en la planeación y ejecución de los ataques aéreos la categoría jurídica del NNA como víctima pasa a un segundo plano, al reseñárseles como daños colaterales, como muertes de responsabilidad tácita de los reclutadores o de los mismos NNA, dado que en el «discurso hegemónico, las víctimas son acusadas de haber provocado los hechos» (Koessl, 2015, p. 109).

\section{Reflexiones finales}

Una revisión del contexto de los NNA combatientes en Colombia dejar ver que los discursos biologicistas, economicistas y terroristas de la guerra tienen la oportunidad de influir en las decisiones militares y políticas que atañen a este tipo de infancia. En otras palabras, producto de la tensión que existe entre el discurso específico del NNA desvinculado de los grupos armados ilegales como víctima y los discursos generales que definen el porqué de la guerra y las motivaciones que impulsan a los actores armados emergen zonas grises de interpretación que pueden derivar en la inhabilitación de la primera noción en los momentos inmediatos de la guerra.

En otras ocasiones, las discrecionalidades de los funcionarios judiciales, políticos y militares han prevalecido a este acuerdo legal, en apego a las lógicas de las formaciones discursivas trabajadas. No se olvide que a los menores de edad que se desmovilizaron de las guerrillas a finales de la década de 1990 y a inicios del siglo xxı muchos jueces los procesaron como infractores de la ley penal (Jiménez, 2013); o que a los NNA pertenecientes al neoparamilitarismo actual hasta hace poco se les pensaba como delincuentes comunes, sin el beneficio de la restitución de sus derechos en el programa de atención del Instituto Colombiano de Bienestar Familiar (Coalico y Comisión Colombiana de Juristas, 2013; Defensoría del Pueblo, 2017).

Adicionalmente, la dinámica militar y política de cómo encarar a la insurgencia en el país devino en que se impusieran significados y categorías

\footnotetext{
${ }^{3}$ Vale decir que sobre este hecho social las Fuerzas Armadas manejan dos discursos contradictorios. Uno se basa en la negación del conocimiento de la existencia de NNA en los campamentos que son bombardeados, como lo declaró recientemente el excomandante de las Fuerzas Armadas, general Nicacio Martínez (Semana, 2019, diciembre 11); al contrario, en una lógica comunicacional contrainsurgente, los mismos voceros de la negación aceptan que las organizaciones armadas ilegales que enfrentan están conformadas en su mayoría por NNA: «Casi la mitad de los integrantes de las disidencias del país son menores de edad. La grave denuncia la hizo el comandante del Ejército Nacional, general Nicacio Martínez» (El Tiempo, 2019, septiembre 14).
} 
muy conectadas con los discursos que aquí analizamos en detrimento de los NNA combatientes. La imposición discursiva de bandolero o chusmero en el pasado para mencionar a los guerrilleros de la década de 1950 (Gómez Muller, 2008), o en las últimas décadas la de narcoterroristas para calificar a las FARC-EP, al ELN o a la oposición política (Gómez-Suárez, 2018) derivaron en una generalización del enemigo carente de diferenciaciones etarias sobre terreno y en una homogeneización explicativa del papel y los orígenes de los NNA y los adultos en la guerra.

Por tal razón, muchas veces las conclusiones de los textos que tratan de los NNA combatientes son casi exactas a las de los adultos (Bácares, 2017) y, si se quiere, repetitivas de algunos de los puntos cardinales del biologicismo, del economicismo y del terrorismo. Sin embargo, como se expuso a lo largo del artículo, acoger dicha operación es muy complejo. Primero, porque la aceptación de estas tesis supone la paulatina erosión de otras formas no oficiales de entender el enganche de los NNA a la guerra, como la de su altruismo político (Rosen, 2005). Segundo, porque trasladar sin una evaluación contextual las nociones generales sobre los NNA combatientes en los conflictos armados, sobre todo africanos, de Europa del este, Asia y del mundo árabe, al escenario colombiano resulta conjeturar que todos los NNA combatientes son iguales o que los atraviesa una suerte de universalidad.

Respecto a esto último, es crucial que las estrategias gubernamentales y las reflexiones académicas asociadas al reclutamiento y los NNA combatientes partan de un hecho elemental señalado por la sociología de la infancia: que cualquier experiencia infanto-adolescente, así como la de los NNA en la guerra, es una construcción social y, en consecuencia, sus demandas y necesidades varían según el grupo armado, la región de origen, la edad, el mando adquirido, el género, el territorio, las dinámicas de la confrontación, entre otros. Por lo cual, pensar el fenómeno descontextualizadamente es una limitación. Lo recomendable sería analizarlo desde abajo, sin por ello desestimar la importancia de la lectura comparada, siempre y cuando los autores y las teorías que devienen de otras realidades se evalúen a partir del escenario histórico que se pretende estudiar.

En resumen, en esteartículose presentaron las divergencias, discrepancias, latencias y la validez de los postulados biologicistas, economicistas y terroristas que hablan de los NNA combatientes en parangón de la realidad colombiana; al igual que se expusieron los riesgos que traerían consigo el aceptar y acoger 
Los discursos biologicistas, economicistas y terroristas de la guerra y sus implicancias...

estos enfoques foráneos, ya que a la hora de desarrollarse una política de contrainsurgencia se puede caer en el desconocimiento de que los NNA combatientes son sujetos de derechos $y$, por tanto, vidas que merecen ser respetadas en los combates y en las operaciones de inteligencia militar.

\section{Referencias bibliográficas}

1. Álvarez, Stephanie y Rettberg, Angelika. (2008). Cuantificando los efectos económicos del conflicto: una exploración de los costos y los estudios sobre los costos del conflicto armado colombiano. Colombia Internacional, 67, pp. 14-37. https://doi. org/10.7440/colombiaint67.2008.01

2. Alvira, Martín. (2008). «Senhor, per les nostres peccatz». Guerra y pecado en la Edad Media. En: Carrasco Manchado, Ana Isabel y Rábade Obradó, María del Pilar (eds.). Pecar en la Edad Media (pp. 97-112). Madrid: Sílex.

3. Bácares, Camilo. (2014). Los pequeños ejércitos. Las representaciones sobre la vida y la muerte de los niños, niñas y jóvenes desvinculados de los grupos armados ilegales colombianos. Bogotá, D. C.: Magisterio.

4. Bácares, Camilo. (2015). Los niños, niñas y jóvenes desvinculados de los grupos armados ilegales en Colombia: ¿Víctimas de la violencia política o sujetos del delito? Estudios Socio-Jurídicos, 17 (2), pp. 233-262. https://doi.org/10.12804/ esj17.02.2015.07

5. Bácares, Camilo. (2017). Siete tesis para una lectura multidimensional y en larga duración del reclutamiento ilícito de los niños, niñas y adolescentes en Colombia. Cuadernos de Marte, 8 (12), pp. 255-316.

6. Bácares, Camilo. (2011). La desaparición forzada de los niños, niñas y adolescentes durante la violencia política en el Perú: una historia de desafiliaciones e impunidad. En: Soto, Ricardo (ed.). El Estado y el ejercicio ciudadano de la infancia en la sociedad peruana en los albores del siglo xxı (pp. 90-143). Huancayo: Universidad Nacional del Centro del Perú.

7. Benposta Colombia-Nación de Muchach@s. (2019). Operación Berlín. Memoria en el olvido. Villavicencio: Benposta Nación de Muchachos.

8. Bonavena, Pablo y Nievas, Flabián. (2006). Las nuevas formas de la guerra, sus doctrinas y su impacto sobre los derechos humanos. Fermentum, 16 (46), pp. 355-371.

9. Boutron, Camille. (2014). De las experiencias invisibles: las mujeres en los Comités de Autodefensa durante el conflicto armado en el Perú (1980-2000). Colombia Internacional, 80, pp. 234-251. https://doi.org/10.7440/colombiaint80.2014.08

10. Butler, Judith. (2006). Vida precaria. El poder del duelo y la violencia. Buenos Aires: Paidós. 
11. Butler, Judith. (2010). Marcos de guerra. Las vidas Iloradas. México, D. F.: Paidós.

12. Calmet, Yazmin y Costa Dal Castel, Karen. (2018). Terrorismo: ¿un concepto contestado? Cuadernos de Marte, 9 (14), pp. 239-262.

13. Cárdenas Sarrias, José Armando. (2005). Los parias de la guerra: análisis del proceso de desmovilización individual. Bogotá, D. C.: Aurora.

14. Centro Nacional de Memoria Histórica (CNMH). (2012). El Placer. Mujeres, coca y guerra en el bajo Putumayo. Bogotá, D. C.: CNMH.

15. Centro Nacional de Memoria Histórica (CNMH). (2017). Una guerra sin edad. Informe nacional de reclutamiento y utilización de niños, niñas y adolescentes en el conflicto armado colombiano. Bogotá, D. C.: CNMH.

16. Coalición contra la vinculación de niños, niñas y jóvenes al conflicto armado en Colombia (Coalico) y Comisión Colombiana de Juristas. (2013). El delito invisible. Criterios para la investigación del delito de reclutamiento ilícito de niños y niñas en Colombia. Bogotá, D. C.: Coalico.

17. Collier, Paul. (2011). El club de la miseria. Qué falla en los países más pobres del mundo. Barcelona: Debolsillo.

18. Collier, Paul; Elliott, V. L; Hegre, Havard; Hoeffler, Anke; Reynal-Querol, Marta y Sambanis, Nicholas. (2004). Guerra civil y políticas de desarrollo. Cómo escapar de la trampa del conflicto. Bogotá, D. C.: Banco Mundial y Alfaomega.

19. Comisión de la Verdad y Reconciliación. (2003a). Sección cuarta: los crímenes

[134] y violaciones de derechos humanos. Capítulo 1: Patrones en la perpetración de los crímenes y de las violaciones de los derechos humanos. 1.8 La violencia contra los niños y niñas. En: Informe final, tomo vı. Recuperado de http://www.cverdad.org.pe/ ifinal/

20. Comisión de la Verdad y Reconciliación. (2003b). Sección primera: exposición general del proceso. Capítulo 3: Los rostros y perfiles de la violencia. En: Informe final, tomo ı. Recuperado de http://cverdad.org.pe/ifinal/

21. Danner, Mark. (2016). Masacre: la guerra sucia en El Salvador. Barcelona: Malpaso.

22. Fondo de las Naciones Unidas para la Infancia (Unicef). (2006). Informe defensorial. Caracterización de las niñas, niños y adolescentes desvinculados de los grupos armados ilegales: Inserción social y productiva desde un enfoque de derechos humanos. La Niñez y sus Derechos, 9. Recuperado de https://www.unicef.org/ colombia/media/2396/file/Caracterizaci \%C3\%B3n\%20de\%20ni \%C3\%B1ez\% 20 desvinculada.pdf

23. Defensoría del Pueblo. (2017). Los invisibles del conflicto: adolescentes víctimas de reclutamiento y utilización dentro del Sistema de Responsabilidad Penal Adolescente-SRPA-. Bogotá, D. C.: Defensoría del Pueblo. 
Los discursos biologicistas, economicistas y terroristas de la guerra y sus implicancias...

24. Degregori, Carlos Iván. (1991). Ayacucho 1980-1983. Jóvenes y campesinos ante la violencia política. Nueva Sociedad, 114, pp. 16-24.

25. El Tiempo. (2019, junio 12). En tiempos de paz, suicidios en FF. MM. no caen. Recuperado de https://www.eltiempo.com/justicia/investigacion/suicidios-deuniformados-vienen-bajando-desde-2010-sanidad-militar-374538

26. El Tiempo. (2019, septiembre 14). Reclutar niños, uno de los peores capítulos del prontuario de «Alonso». Recuperado de https://www.eltiempo.com/justicia/ conflicto-y-narcotrafico/casi-la-mitad-de-las-disidencias-de-farc-son-menores-deedad-412306

27. Fajardo, Luis. (2011). Los mercaderes de la muerte en Colombia: multinacionales y derechos humanos. VIel, 6 (1), pp. 1-68. https://doi.org/10.15332/ s1909-0528.2011.0001.05

28. Fernández de Gurmendi, Silvia. (1999). Iniciativas de las Naciones Unidas para combatir el terrorismo internacional. Relaciones Internacionales, 9 (17), pp. 1-19.

29. Fromm, Erich. (2004). Anatomía de la destructividad humana. México, D. F.: Siglo XXI.

30. Grupo Aéreo del Oriente (Gaori). (2019, junio 28). Más de 130000 volantes de desmovilización fueron lanzados durante primer semestre de 2019 en Vichada y Guainía. Fuerza Aérea Colombiana. Recuperado de https://www.fac.mil. co/m\% C3\%A1s-de-130000-volantes-de-desmovilizaci \%C3\%B3n-fueron-lanzadosdurante-primer-semestre-de-2019-en-vichada

31. Gómez Muller, Alfredo. (2008). La reconstrucción de Colombia. Escritos políticos. Medellín: La Carreta. https://doi.org/10.30778/2018.44

32. Gómez-Suárez, Andrei. (2018). Genocidio, geopolítica y redes transnacionales. Una con-textualización de la destrucción de la Unión Patriótica en Colombia. Bogotá, D. C.: Universidad de los Andes.

33. Hodge, Eduardo. (2019). Disensos e imprecisiones del concepto terrorismo: cuestionamientos a los enfoques teóricos tradicionales. Revista Relaciones Internacionales, Estrategia y Seguridad, 14 (1), pp. 223-236. https://doi.org/10.18359/ ries.3707

34. Hudson, Rex. (1999). The Sociology and Psychology of Terrorism: Who Becomes a Terrorist and Why? Washington, D. C.: The Library of Congress. https:// doi.org/10.1037/e622272007-001

35. Human Rights Watch. (2004). Aprenderás a no llorar. Niños Combatientes en Colombia. Recuperado de https://www.hrw.org/sites/default/files/reports/colombia ninos.pdf

36. Jaramillo, Carlos Eduardo. (2007). Los guerreros invisibles. El papel de los niños en los conflictos civiles en el siglo xIx en Colombia. En: Rodríguez, Pablo y Mannarelli, Emma (eds.). Historia de la infancia en América Latina (pp. 231-246). Bogotá, D. C.: Universidad Externado de Colombia. 
37. Jilmar, Carlos; Amador, Juan Carlos y Delgadillo, Ingrid. (2010). Emergencias de la memoria. Dos estudios sobre la infancia, la escuela y la violencia. Bogotá, D. C.: Universidad Distrital Francisco José de Caldas.

38. Jiménez, Absalón. (2013). Infancia. Ruptura y discontinuidades de su historia en Colombia. Bogotá, D. C.: Ecoe.

39. Jurado, Juan Carlos. (2004). Soldados, pobres y reclutas en las guerras civiles colombianas. Revista de Indias, LxIv (232), pp. 673-696. https://doi.org/10.3989/ revindias.2004.i232.430

40. Kaldor, Mary. (2001). Las nuevas guerras: la violencia organizada en la era global. Barcelona: Tusquets.

41. Koessl, Manfredo. (2015). Violencia y habitus. Paramilitarismo en Colombia. Bogotá, D. C.: Siglo del Hombre. https://doi.org/10.4000/books.sdh.531

42. Lair, Eric. (2003). Reflexiones acerca del terror en los escenarios de guerra interna. Estudios Sociales, 15, pp. 88-108. https://doi.org/10.7440/res15.2003.06

43. Manrique, Nelsón. (1989). La década de la violencia. Márgenes, 5-6, pp. 137-182.

44. Martín-Baró, Ignacio. (2000). Psicología social de la guerra: trauma y terapia. San Salvador: UCA.

45. Melvern, Linda. (2007). Un pueblo traicionado. El papel de Occidente en el genocidio de Ruanda. Barcelona: Intermón Oxfam.

46. Molano, Alfredo. (1999). Trochas y fusiles. Bogotá, D. C.: El Áncora.

47. Molano, Alfredo. (2017, febrero 17). Los niños y la guerra. El Espectador. Recuperado de https:/www.elespectador.com/opinion/columna-48

48. Molano, Hilda. (2019, noviembre 9). Los niños de la guerra. Cerosetenta. Recuperado de https://cerosetenta.uniandes.edu.co/los-ninos-de-la-guerra/

49. Montemayor, Carlos. (2007). La guerrilla recurrente. México, D. F.: Debate.

50. Münkler, Herfried. (2005). Viejas y nuevas guerras. Asimetría y privatización de la violencia. Madrid: Siglo xxı.

51. Nievas, Flabián. (2015). Terrorismo: en búsqueda del concepto. Cuadernos de Marte, 6 (9), pp. 173-202.

52. Observatorio de Procesos de Desarme, Desmovilización y Reintegración (ODDR). (2012). Salidas de Integrantes de Organizaciones Guerrilleras 2002-2011. Bogotá, D. C.: Universidad Nacional de Colombia.

53. Organización de las Naciones Unidas (ONU). Consejo de Seguridad. S/2019/1017. (31 de diciembre de 2019). Los niños y el conflicto armado en Colombia: Informe del Secretario General. Recuperado de https://www.refworld.org. es/docid/5e59bf4c4.html

54. Palacio, Roberto. (2003). La agresión y la guerra desde el punto de vista de la etología y la obra de Konrad Lorenz. Revista de Estudios Sociales, 14, pp. 52-62. https://doi.org/10.7440/res14.2003.04 
Los discursos biologicistas, economicistas y terroristas de la guerra y sus implicancias...

55. Pécaut, Daniel. (2001). Guerra contra la sociedad. Bogotá, D. C.: Espasa.

56. Pizarro, Eduardo. (2002). Colombia: ¿guerra civil, guerra contra la sociedad, guerra antiterrorista o guerra ambigua? Análisis Político, 46, pp. 164-179.

57. Potthast, Bárbara. (2005). Niños soldados y niñas famélicas en la Guerra del Paraguay. En: Potthast, Bárbara y Carreras, Sandra (eds.). Entre la familia, la sociedad y el Estado. Niños y jóvenes en América Latina (siglos XIX-XX) (pp. 89-114). Madrid: Biblioteca Iberoamericana.

58. Ramírez Batalla, Miguel Ángel. (2015). Proinde rem militarem colant. Guerra, sociedad y política en la república romana. En: Ortega, Martha (coord.). Guerra y terrorismo. Aproximaciones históricas (pp. 13-38). Barcelona: Anthropos.

59. Ramírez, Paula. (2010). El reclutamiento de menores en el conflicto armado colombiano. Aproximación al crimen de guerra. Derecho Penal y Criminología, 31 (90), pp. 115-136. Recuperado de https://revistas.uexternado.edu.co/index.php/ derpen/article/view/452

60. Ramírez, Renzo y Jiménez, Hernán David. (2014). Guerra y paz: una revisión conceptual. Una interpretación para el caso colombiano. Historia Caribe, Ix (24), pp. 163-197. Recuperado de http://investigaciones.uniatlantico.edu.co/revistas/index. php/Historia_Caribe/article/view/1111

61. Ramonet, Ignacio. (2005). Irak. Historia de un desastre. Caracas: Random House Mondadori.

62. Reina, Carlos. (2012). Reclutamiento y vida cotidiana de niños y jóvenes en Colombia durante el siglo xIx: aproximaciones generales. Infancias Imágenes, 11 (2), pp. 59-68.

63. Semana. (2019, diciembre 11). Lo que se sabe del bombardeo del Ejército en el que murieron al menos ocho niños. Recuperado de https://www.semana.com/ nacion/articulo/lo-que-se-sabe-del-bombardeo-del-ejercito-en-el-que-murieron-almenos-ocho-ninos/639890

64. Ródenas, Pablo. (2003). Repensar la guerra (legitimidad y legitimación de las nuevas formas de violencia bélica). En: Riutort, Bernat (ed.). Conflictos bélicos y nuevo orden mundial (pp. 9-52). Barcelona: Icaria.

65.Rodríguez Urrego, Sandra Marcela. (2008). Repertorios interpretativos de desmovilizados en el Programa de Reinserción en torno a la política y lo político (20022008). Entre la política y el mercenarismo. [Tesis inédita de maestría]. Universidad de los Andes, Bogotá, D. C.

66. Rojas, Tatiana. y Aristizábal, Yénifer. (2019). ELN y disidencias de las Farc: el "Coco» de los niños en 19 zonas del país. Semana. Recuperado de https://www. semana.com/educacion/articulo/el-regreso-del-reclutamiento-infantil-por-parte-degrupos-armados/615427

67. Romero, Antonio José. (2008). Guerra y paz. Revista Mexicana de Sociología, 70 (8), pp. 589-617. 
68. Rosen, David. (2005). Armies of the Young: Child Soldiers in War and Terrorism. New Brunswick: Rutger University.

69. Rosen, David. (2015). Child soldiers in the Western Imagination. From patriots to victims. New Brunswick: Rutger University.

70. Rubio, Mauricio. (2007). Pandillas, rumba y actividad sexual. Desmitificando la violencia juvenil. Bogotá, D. C.: Universidad Externado de Colombia.

71. Rubio, Mauricio y Salcedo, Eduardo. (2006). Genes, género y violencia. Borradores de Método, 34, pp. 1-35.

72. Rueda, Zenaida. (2009). Confesiones de una guerrillera. Bogotá, D. C.: Planeta.

73. Sánchez Arévalo, Nicolás. (2019, febrero 9). No es la primera vez que mueren niños en bombardeos de la Fuerza Pública. El Espectador. Recuperado de https:// www.elespectador.com/colombia2020/pais/no-es-la-primera-vez-que-mueren-ninosen-bombardeos-de-la-fuerza-publica-articulo-890185

74. Sánchez, Fabio José y Díaz, Ana María. (2005). Los efectos del conflicto armado en el desarrollo social colombiano, 1990-2002. Bogotá, D. C.: Universidad de los Andes.

75. Springer, Natalia. (2012). Como cordero entre lobos. Del uso y reclutamiento de niñas, niños y adolescentes en el marco del conflicto armado y la criminalidad en Colombia. Bogotá, D. C.: Springer. Recuperado de http://www. centrodememoriahistorica.gov.co/descargas/informe_comoCorderosEntreLobos.pdf

[138] 76. Toche Medrano, Eduardo. (2008). Guerra y democracia. Los militares peruanos y la construcción nacional. Lima: Desco, Clacso.

77. Torres, Henry. (2010). El concepto de terrorismo, su inexistencia o inoperancia: la apertura a la violación de derechos humanos. Diálogos de Saberes, 32, pp. 77-90.

78. Torrijos, Vicente. (2015). Cartografía del conflicto: pautas interpretativas sobre la evolución del conflicto irregular colombiano. En: Comisión Histórica del Conflicto y sus Víctimas. Contribución al entendimiento del conflicto armado en Colombia (pp. 589-627). Bogotá, D. C.: Imprenta Nacional de Colombia.

79. Tovar Pinzón, Hermes. (2001). Tras las huellas del soldado Pablo. En: Sánchez, Gonzalo y Aguilera, Mario (eds.). Memorias de un país en guerra. Los Mil Días 1899-1902 (pp. 143-172). Bogotá, D. C.: Planeta.

80. Uceda, Ricardo. (2004). Muerte en el pentagonito. Los cementerios secretos del Ejército Peruano. Bogotá, D. C.: Planeta.

81. Uesseler, Rolf. (2007). La guerra como negocio. Cómo las empresas militares privadas destruyen la democracia. Barcelona: Belacqva.

82. Ugarriza, Juan y Nussio, Enzo. (2015). ¿Son los guerrilleros diferentes de los paramilitares? Una integración y validación sistemática de estudios motivacionales en Colombia. Análisis Político, 85, pp. 189-211. https://doi.org/10.15446/anpol. v28n85.56254 
83. Uribe, María Victoria. (2007). Salvo el poder todo es ilusión. Mitos de origen: Tigres Tamiles de Sri Lanka, Fuerzas Armadas Revolucionarias de Colombia, Iris Republican Army. Bogotá, D. C.: Pontificia Universidad Javeriana.

84. Vega-Centeno, Imelda. (1994). Género y política: a propósito de la mujer en Sendero Luminoso. Boletín Americanista, 44, pp. 207-213.

85. Verdadabierta.com. (2016, agosto 27). «Operación Berlín»: historias de reclutados y sobrevivientes. Recuperado de https://verdadabierta.com/operacionberlin-historias-de-reclutados-y-sobrevivientes/

86. Verdadabierta.com. (2017, febrero 3). ¿Qué empresas bananeras podrían responder por crímenes de lesa humanidad? Recuperado de https://verdadabierta. com/que-empresas-bananeras-podrian-responder-por-crimenes-de-lesa-humanidad/

87. Verdadabierta.com. (2019, noviembre 8). Niños bombardeados en Caquetá, otro caso fallido de prevención de riesgo. Recuperado de https://verdadabierta.com/ ninos-bombardeados-en-caqueta-otro-caso-fallido-de-prevencion-del-riesgo/

88. Villegas, Myrna. (2016). Contribuciones para un concepto de terrorismo en el derecho penal chileno. Política Criminal, 11 (21), pp. 140-172. https://doi. org/10.4067/s0718-33992016000100006

89. Wills, María.Emma. (2008, junio 22). Los engranajes de la guerra. EI Espectador. Recuperado de https://www.elespectador.com/opinion/los-engranajesde-la-guerra-columna-21380

90. Winterberg, Yury y Winterberg, Sonya. (2015). Los niños en la primera guerra mundial. Bogotá, D. C.: Planeta. 